\title{
Correlation between obesity and metabolic syndrome-related factors and cecal intubation time during colonoscopy
}

This article was published in the following Dove Press journal:

Clinical and Experimental Gastroenterology

5 January 2017

Number of times this article has been viewed

Ryo Kawasato'

Shinichi Hashimoto'

Tomohiro Shirasawa'

Atsushi Goto'

Takeshi Okamoto'

Jun Nishikawa ${ }^{2}$

Isao Sakaida'

'Department of Gastroenterology and Hepatology, ${ }^{2}$ Department of

Laboratory Science, Yamaguchi

University Graduate School of

Medicine, Yamaguchi, Japan
Correspondence: Shinichi Hashimoto Department of Gastroenterology and Hepatology, Yamaguchi University Graduate School of Medicine, I-I-I Minami-Kogushi, Ube, Yamaguchi 7558505, Japan.

$\mathrm{Tel}+8 \mid 836222239$

$\mathrm{Fax}+81836222303$

Email has-333@yamaguchi-u.ac.jp
Purpose: To investigate which colonoscopy (CS) cases should be presided over by endoscopists in training, using factors including obesity and metabolic syndrome.

Patients and methods: Items investigated were sex, age, body mass index (BMI), waist circumference, hypertension, diabetes, hyperlipidemia, history of abdominal surgery (excluding colectomy), colon diverticulosis, prescription of antithrombotic agents, and quality of bowel preparation. Expert physicians were defined as those with at least 9 years of endoscopy experience; all other physicians were defined as being in training. In a retrospective analysis, cases in which a physician in training reached the cecum within 15 minutes without requiring the involvement of the supervising physician were defined as eligible cases over which a physician in training should preside, while other cases were defined as non-eligible.

Results: Overall, 813 CS cases were analyzed. Males $(P<0.0001)$, cases started by an expert physician $(P<0.0001)$, cases of no fellow physician involvement $(P<0.0001)$, and cases with good bowel preparation $(P<0.0001)$ had significantly shorter cecal intubation times. Of the 562 cases presided over by a physician in training, 194 were deemed eligible and 368 non-eligible. The eligible cases had a higher proportion of males $(P=0.017)$, younger age $(P=0.033)$, higher BMI $(P=0.034)$, and higher rates of hypertension $(P=0.001)$ and good bowel preparation $(P=0.001)$. In analysis by sex, males demonstrated significantly more eligible cases among younger patients $(P=0.009)$ and those with good bowel preparation $(P=0.008)$, while there were significantly more eligible cases among females with hypertension ( $P=0.004)$.

Conclusion: It may be useful to select CS cases for physicians considering sex, age, BMI, hypertension, and bowel preparation.

Keywords: physician training, body mass index, hypertension, bowel preparation

\section{Introduction}

Colon cancer frequency has continued to increase in Japan in recent years, becoming the third highest cause of cancer death in males and number one in females in 2014 . Every year, there are over 40,000 deaths due to colon cancer, and reducing mortality rates has become a major goal. ${ }^{1,2}$

Excision of colon polyps using colonoscopy (CS) suppresses the incidence and mortality of colon cancer, ${ }^{3}$ increasing the importance of CS. However, it is important to avoid patient refusal due to prolonged examination times and excessive pain. The development of physicians who are expert at CS can be valuable to improving these outcomes. The cecal intubation success rate of less-experienced physicians has been reported to range from $56 \%$ to $75 \%,{ }^{4}$ and such physicians have been reported to 
have a higher risk of perforating the colon when inserting the colonoscope. ${ }^{5}$ Colon models and simulators are current methods for practicing CS, ${ }^{6}$ but it is necessary to accumulate experience with real cases for solid mastery of the technique. If physicians in the process of learning the technique can start by presiding over cases with a low level of difficulty, prolonged examination times and excess patient pain can be avoided. However, there are no clear standards, and in clinical practice this process is handled subjectively by instructors in each facility.

Cecal intubation time (CIT) has been used as an indicator of the difficulty of endoscopic insertion. ${ }^{7}$ Not only the endoscopic operation technique of the physician, but also patient factors have been reported to affect CS difficulty. Reported CIT-related factors include sex, age, history of abdominal or gynecological surgery, body mass index (BMI), waist circumference, visceral adipose tissue, quality of bowel preparation, and involvement of fellow physicians. ${ }^{8-12}$

An examination of the reports of factors related to CIT does not reveal a unified view, and there are several causes of differing results between the reports. Some reports indicate that visceral adipose tissue, BMI, and waist circumference are relevant, but no reports also investigated the metabolic syndrome-related factors of hypertension, diabetes, and hyperlipidemia. Additionally, few reports separated expert physicians and physicians in training with respect to endoscopic procedure. ${ }^{13}$ In this study, we thus performed a retrospective investigation of many factors, including metabolic syndrome-related disorders, with respect to the characteristics of cases over which endoscopists being trained in CS should preside, using CIT as an indicator.

\section{Material and methods Ethical considerations}

The study was reviewed and approved by the Ethical Committee on Human Research at Yamaguchi University Hospital (H27-181). Patients were not required to give informed consent to the study because the analysis used anonymous clinical data that were obtained after each patient agreed to initial treatment by written consent.

\section{Patients}

The subjects were new patients who had undergone colonoscopic examination at Yamaguchi University Hospital from April 2011 to December 2014, excluding cases of emergency endoscopy. The examination excluded, 1) patients with a history of colectomy, 2) patients in whom the cecum could not be reached due to advanced colon cancer or a similar condition, and 3) patients for whom information was lacking for at least one of the items under investigation.

\section{CS}

On the day prior to the examination, the patients fasted from $9 \mathrm{pm}$ and took two tablets of sennoside (Sawai Pharmaceutical Co Ltd, Osaka, Japan) as a pretreatment. On the day of the examination, the patients took two tablets of metoclopramide (Elieten; Takata Pharmaceutical Company Ltd, Saitama, Japan) and a total of 2,000 $\mathrm{mL}$ of polyethylene glycol (Niflec ${ }^{\circledR}$; Ajinomoto Pharmaaceuticals Co Ltd, Tokyo, Japan). The endoscopes used were CF-H260AZI, CF-H260AI, CFQ260DI, PCF-Q260AZI, PCF-Q260J, and PCF-PQ260I (Olympus Corporation, Tokyo, Japan). $\mathrm{CO}_{2}$ insufflation was used for all cases. Sedatives and antispasmodics were essentially unused. The CIT was calculated by capturing one photograph immediately before endoscope insertion and capturing another photograph when it was verified that the cecum had been reached. All patients received an explanation of the risks of hemorrhaging and perforation from colonoscopic examination, and written consent was obtained.

Of the physicians performing the endoscopy, those specializing in the treatment of gastrointestinal disease and with at least 9 years of endoscopic experience were considered expert physicians, while all others were defined as physicians in training. The fellow physician was involved in cases when an expert physician judged that deep insertion was difficult after at least 15 minutes of insertion time, when patient pain was high even before 15 minutes had elapsed, and when fluctuating vital signs were noted. Diverticula were considered to be present when confirmed in the endoscopic findings, regardless of location or number. The quality of bowel preparation was classified as good (no or small quantities of liquid which occupied less than one-third of colon lumen) or poor (large quantities of liquid which occupied more than one-third of colon lumen or presence of solid feces).

\section{Clinical background}

Information was gathered using a survey prior to endoscopy. The items were sex, age, hypertension, diabetes, hyperlipidemia, history of abdominal surgery (excluding colon resection), and prescription of antithrombotic agents.

\section{Definition of eligible cases}

A CIT of less than 15 minutes has been reported to be a reasonable standard for measuring technical ability, ${ }^{12,14}$ and therefore in this investigation, cases in which a physician in training reached the cecum within 15 minutes without 
requiring involvement of a fellow physician were defined as eligible cases for a physician in training, while all other cases were considered non-eligible cases.

\section{Statistical analysis}

Unpaired $t$-tests, $\chi^{2}$ tests, and simple logistic regression analyses were used in the univariate analysis. For multivariate analysis, multiple regression analysis was used for the insertion time, and multiple logistic regression analysis was used for the investigation of eligible cases. The statistical significance threshold for multivariate analysis was $P<0.05$. STATA13 software (StataCorp LP, College Station, TX, USA) was used for all statistical analyses.

\section{Results}

Of the 4271 cases of CS performed during the target time period, 914 were new patients, excluding emergency examinations. Of these 914 cases, there was a history of colectomy in 50 patients, the cecum could not be reached due to advanced colon cancer in 13 patients, and information for at least one of the investigated items was missing for 38 patients, for a total of 101 excluded cases. The final count for the investigation was 813 cases (Figure 1).

There were 18 endoscopists performing CS, of which five were expert physicians and 13 were physicians in training.
The clinical backgrounds of the target cases are shown in Table 1. There were 456 males (56\%) and 357 females (44\%), with an average age (mean \pm standard deviation [SD]) of $63.3 \pm 10.2$ years. An expert physician started 251 cases $(30.9 \%)$, while a physician in training started 562 cases (69.1\%). No complications were found relating to endoscope

Table I Patient characteristics

\begin{tabular}{|c|c|}
\hline & 813 cases \\
\hline Sex (n [\%], male/female) & $456 / 357(56 \% / 44 \%)$ \\
\hline Age (years) mean $\pm S D$ & $63.3 \pm 10.2$ \\
\hline Height $(\mathrm{cm})$ mean \pm SD & $161.4 \pm 8.87$ \\
\hline Weight $(\mathrm{kg})$ mean $\pm \mathrm{SD}$ & $59.8 \pm 28.5$ \\
\hline BMI $\left(\mathrm{kg} / \mathrm{m}^{2}\right)$ mean $\pm \mathrm{SD}$ & $22.8 \pm 9.18$ \\
\hline Waist circumference $(\mathrm{cm})$ mean $\pm S D$ & $80.9 \pm 10.8$ \\
\hline Hypertension (n [\%], yes/no) & $343 / 470(42.1 \% / 57.9 \%)$ \\
\hline Diabetes (n [\%], yes/no) & $126 / 687(\mid 5.5 \% / 84.5 \%)$ \\
\hline Hyperlipidemia (n [\%], yes/no) & $159 / 654(19.7 \% / 80.3 \%)$ \\
\hline Antithrombotics (n [\%], yes/no) & $119 / 694(14.6 \% / 85.4 \%)$ \\
\hline History of abdominal surgery (n [\%], yes/no) & $356 / 457(43.7 \% / 56.3 \%)$ \\
\hline Diverticula (n, yes/no) & $236 / 577(29 \% / 7 / \%)$ \\
\hline $\begin{array}{l}\text { Expert physician/physician in training } \\
\text { (n [\%], yes/no) }\end{array}$ & $25 \mathrm{I} / 562(30.9 \% / 69.1 \%)$ \\
\hline $\begin{array}{l}\text { Colonoscope operator ( } \mathrm{n}[\%] \text {, } \\
\text { attending physician/fellow physician) }\end{array}$ & $695 / 118(85.5 \% / / 4.5 \%)$ \\
\hline Bowel preparation (n [\%], good/poor) & $729 / 84(89.7 \% / 10.3 \%)$ \\
\hline
\end{tabular}

Abbreviation: BMI, body mass index.

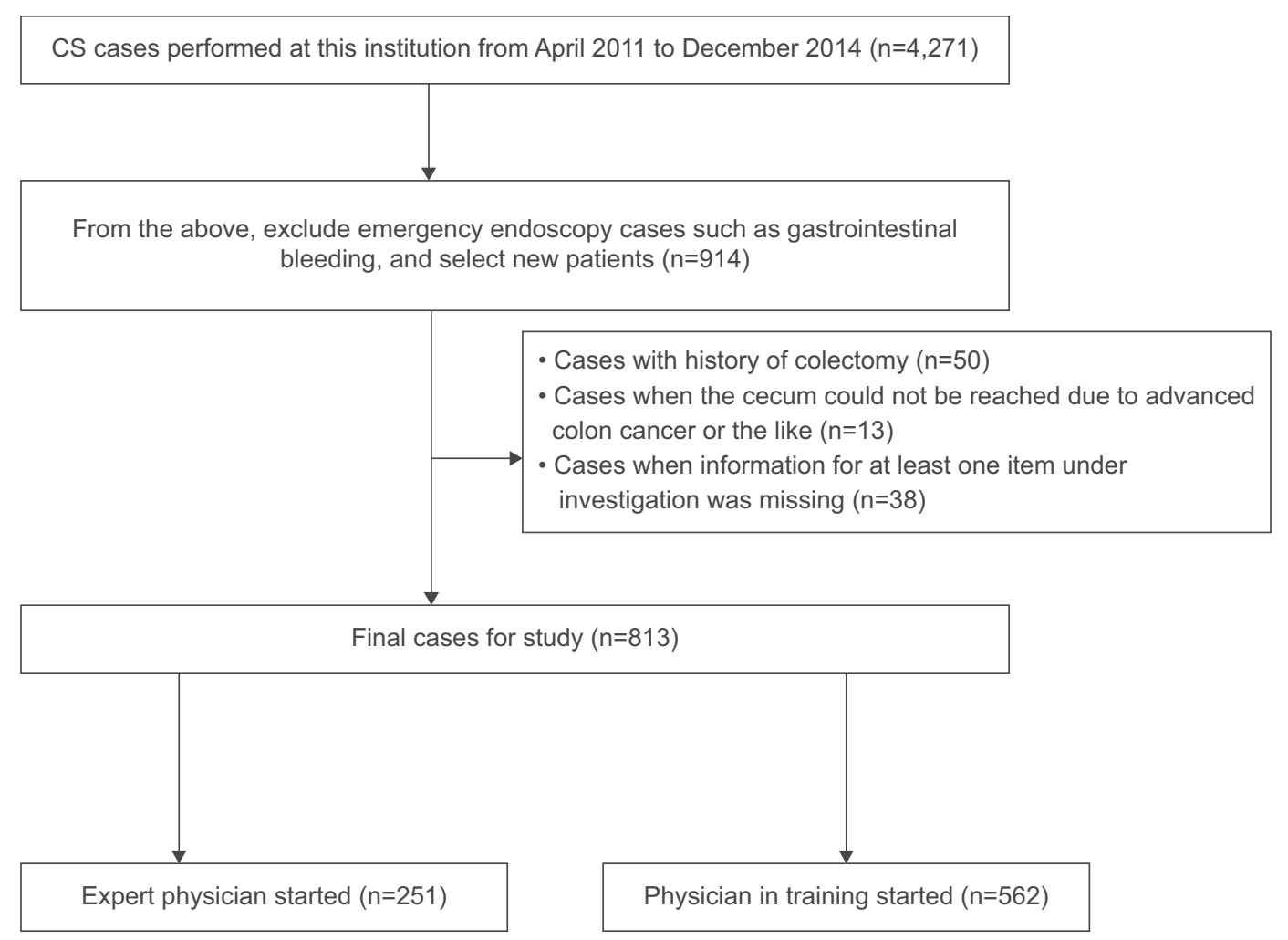

Figure I Assignment of subjects in the present study. 
insertion for any patients. The average CIT \pm SD for all the cases was $1,120 \pm 694.0 \mathrm{~s}$.

Univariate analysis was performed for the relationship between each investigated factor and the CIT (Table 2). The CIT was significantly shorter in males $(1,044 \pm 656.4$ vs $1,216 \pm 728.7 \mathrm{~s} ; P=0.001)$, cases having hypertension

Table 2 Univariate analysis of the factors associated with cecal intubation time during colonoscopy

\begin{tabular}{|c|c|c|c|c|}
\hline & n (\%) & $\begin{array}{l}\text { CIT, } \\
\text { average } \pm \\
\text { SD (s) }\end{array}$ & Median (s) & $P$-value \\
\hline Total & $813(100)$ & $1,120 \pm 694.0$ & 961 & \\
\hline \multicolumn{5}{|l|}{ Sex } \\
\hline Male & $456(56)$ & $\mathrm{I}, 044 \pm 656.4$ & 888 & \\
\hline Female & $357(44)$ & $1,216 \pm 728.7$ & 1,066 & 0.001 \\
\hline \multicolumn{5}{|l|}{ Age (years) } \\
\hline$<65$ & $396(48.6)$ & $1,095 \pm 687.0$ & 929 & \\
\hline$\geq 65$ & $4 \mid 7(5 \mid .4)$ & $\mathrm{I}, 143 \pm 700.7$ & 999 & 0.315 \\
\hline \multicolumn{5}{|l|}{ BMI $\left(\mathbf{k g} / \mathbf{m}^{2}\right)$} \\
\hline$<25$ & 648 (79.7) & $\mathrm{I}, 128 \pm 704.7$ & 974 & \\
\hline$\geq 25$ & $165(20.3)$ & $1,083 \pm 650.6$ & 903 & 0.434 \\
\hline \multicolumn{5}{|l|}{ Waist } \\
\hline \multicolumn{5}{|l|}{ circumference } \\
\hline \multicolumn{5}{|l|}{$(\mathrm{cm})$} \\
\hline$<85$ & $516(63.5)$ & $\mathrm{I}, 140 \pm 702.8$ & 986 & \\
\hline$\geq 85$ & $297(36.5)$ & $\mathrm{I}, 082 \pm 677.7$ & 913 & 0.252 \\
\hline \multicolumn{5}{|l|}{ Hypertension } \\
\hline Yes & $343(42.9)$ & $1,056 \pm 669.4$ & 866 & \\
\hline No & $470(57.1)$ & $\mathrm{I}, 164 \pm 708.4$ & 1,018 & 0.026 \\
\hline \multicolumn{5}{|l|}{ Diabetes } \\
\hline Yes & $126(\mid 5.5)$ & $I,|4| \pm 655.6$ & $\mathrm{I}, 007$ & \\
\hline No & $687(84.5)$ & 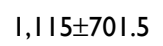 & 960 & 0.682 \\
\hline \multicolumn{5}{|l|}{ Hyperlipidemia } \\
\hline Yes & $159(19.6)$ & $I, 047 \pm 636.1$ & 935 & \\
\hline No & $654(80.4)$ & $1,136 \pm 706.6$ & 963 & 0.122 \\
\hline \multicolumn{5}{|l|}{ History of } \\
\hline \multicolumn{5}{|l|}{ abdominal surgery } \\
\hline No & $457(56.2)$ & $1,118 \pm 691.5$ & 963 & \\
\hline Yes & $356(43.8)$ & $1,120 \pm 697.8$ & 952 & 0.967 \\
\hline \multicolumn{5}{|l|}{ Diverticula } \\
\hline Yes & $236(27)$ & $\mathrm{I}, 09 \mathrm{I} \pm 659.4$ & 952 & \\
\hline No & $577(73)$ & $\mathrm{I}, 130 \pm 707.7$ & 963 & 0.455 \\
\hline \multicolumn{5}{|l|}{ Physician } \\
\hline Physician in training & $562(69.1)$ & $1,264 \pm 695.8$ & $|| 3 \mid$, & \\
\hline Expert physician & $25 \mathrm{I}(30.9)$ & $792 \pm 568.3$ & 626 & $<0.0001$ \\
\hline \multicolumn{5}{|l|}{ Colonoscope } \\
\hline \multicolumn{5}{|l|}{ operator } \\
\hline Attending physician & $694(85.3)$ & $998 \pm 607.3$ & 856 & \\
\hline Fellow physician & $118(14.7)$ & $\mathrm{I}, 830 \pm 747.3$ & $\mathrm{I}, 707$ & $<0.0001$ \\
\hline \multicolumn{5}{|l|}{ Bowel } \\
\hline \multicolumn{5}{|l|}{ preparation } \\
\hline Good & 729 (89.7\%) & $1,050 \pm 635.3$ & 903 & \\
\hline Poor & $84(10.3 \%)$ & $1,715 \pm 876.8$ & 1,538 & $<0.0001$ \\
\hline
\end{tabular}

Abbreviations: BMI, body mass index; CIT, cecal intubation time.
$(1,056 \pm 669.4$ vs $1,164 \pm 708.4 \mathrm{~s} ; P=0.026)$, cases started by an expert physician (792 \pm 568.3 vs $1,264 \pm 695.8 \mathrm{~s} ; P<0.0001)$, cases of no fellow physician involvement $(998 \pm 607.3$ vs $1,830 \pm 747.3 \mathrm{~s} ; P<0.0001)$, and cases with good bowel preparation $(1,050 \pm 635.3$ vs $1,715 \pm 876.8 \mathrm{~s} ; P<0.0001)$. When multivariate analysis was performed for the items found to have a significant difference in univariate analysis, a significant difference was found for males $(P<0.0001)$, cases started by an expert physician $(P<0.0001)$, cases of no fellow physician involvement $(P<0.0001)$, and cases with good bowel preparation $(P<0.0001)$ (Table 3$)$.

Of the 562 cases begun by a physician in training, 194 were judged to be eligible and 368 were non-eligible. The eligible cases had a higher proportion of males (38.5\% vs $29.4 \% ; P=0.024)$, a higher BMI (23.2 \pm 3.8 vs $\left.22.8 \pm 13.1 \mathrm{~kg} / \mathrm{m}^{2} ; P=0.001\right)$, a larger waist circumference $(82.6 \pm 10.9$ vs $80.0 \pm 11.1 \mathrm{~cm} ; P=0.009)$, a higher incidence of hypertension (53.6\% vs 38.0\%; $P<0.0001)$, and a higher rate of good bowel preparation $(95.4 \%$ vs $84.8 \%$; $P<0.0001)$ (Table 4). In the multivariate analysis of items with a $P$ value $<0.1$, a significant difference was found for male sex

Table 3 Multivariate analysis of the factors associated with cecal intubation time during colonoscopy

\begin{tabular}{lllll}
\hline & Coef. & SE & P-value & $95 \%$ CI \\
\hline Sex & 151.293 & 41.207 & $<0.0001$ & $70.407,232.179$ \\
Hypertension & -79.991 & 41.527 & 0.054 & $-161.505,1.524$ \\
$\begin{array}{l}\text { Physician } \\
\text { experience }\end{array}$ & -343.725 & 45.189 & $<0.0001$ & $-432.427,-255.023$ \\
$\begin{array}{l}\text { Colonoscope } \\
\text { operator }\end{array}$ & 673.666 & 59.558 & $<0.0001$ & $556.760,790.573$ \\
Bowel preparation & 555.948 & 67.246 & $<0.0001$ & $423.951,687.946$ \\
\hline
\end{tabular}

Abbreviations: $\mathrm{Cl}$, confidence interval; Coef, coefficient; SE, standard error.

Table 4 Univariate analysis of the factors in the eligible cases and non-eligible cases

\begin{tabular}{|c|c|c|c|}
\hline $\begin{array}{l}\text { Factor under } \\
\text { investigation }\end{array}$ & Eligible cases & $\begin{array}{l}\text { Non-eligible } \\
\text { cases }\end{array}$ & $P$-value \\
\hline Sex (male/female) & $122 / 72$ & $195 / 173$ & 0.024 \\
\hline Age (years) mean $\pm S D$ & $61.9 \pm 10.4$ & $63.6 \pm 10.2$ & 0.054 \\
\hline $\mathrm{BMI}\left(\mathrm{kg} / \mathrm{m}^{2}\right)$ mean $\pm \mathrm{SD}$ & $23.2 \pm 3.8$ & $22.8 \pm 13.1$ & 0.001 \\
\hline Waist circumference $(\mathrm{cm})$ & $82.6 \pm 10.9$ & $80.0 \pm 11.1$ & 0.009 \\
\hline Hypertension (\%) (yes/no) & $53.6 \%(104 / 90)$ & $38.0 \%(140 / 228)$ & $<0.0001$ \\
\hline Diabetes (\%) (yes/no) & $15.4 \%(30 / 164)$ & $\mid 5.5 \%(57 / 3 \mid 1)$ & 0.994 \\
\hline Hyperlipidemia (\%) (yes/no) & $18.6 \%(36 / 158)$ & $18.5 \%(68 / 300)$ & 0.982 \\
\hline $\begin{array}{l}\text { History of abdominal } \\
\text { surgery }(\%)(\text { yes/no) }\end{array}$ & $37.1 \%(72 / 122)$ & $42.1 \%(155 / 213)$ & 0.250 \\
\hline $\begin{array}{l}\text { Taking antithrombotics (\%) } \\
\text { (yes/no) }\end{array}$ & $12.9 \%(25 / 169)$ & $15.5 \%(57 / 3 \mid \mathrm{I})$ & 0.407 \\
\hline Diverticula (\%) (yes/no) & $33.0 \%(64 / 130)$ & $30.2 \%(111 / 257)$ & 0.492 \\
\hline $\begin{array}{l}\text { Bowel preparation (\%) } \\
\text { (good/poor) }\end{array}$ & $95.4 \%(185 / 9)$ & $84.8 \%(3 \mid 2 / 56)$ & $<0.0001$ \\
\hline
\end{tabular}


$(P=0.017)$, younger age $(P=0.033)$, higher BMI $(P=0.034)$, cases with hypertension $(P=0.001)$, and cases with good bowel preparation $(P=0.001)$ (Table 5$)$.

When backgrounds were compared by sex, many differences were detected, as shown in Table 6. A univariate

Table 5 Multivariate analysis of the factors in the eligible cases and non-eligible cases

\begin{tabular}{lllll}
\hline & Odds Ratio & SE & $P$-value & 95\% Cl \\
\hline Sex & 1.676 & 0.364 & 0.017 & $1.095,2.565$ \\
Age & 1.020 & 0.094 & 0.033 & $1.002,1.039$ \\
BMI & 0.897 & 0.046 & 0.034 & $0.812,0.992$ \\
Waist circumference & 1.021 & 0.018 & 0.223 & $0.987,1.057$ \\
Hypertension & 0.523 & 0.102 & 0.001 & $0.357,0.766$ \\
Bowel preparation & 3.702 & 1.402 & 0.001 & $1.762,7.777$ \\
\hline
\end{tabular}

Abbreviations: $\mathrm{BMI}$, body mass index; $\mathrm{Cl}$, confidence interval; $\mathrm{SE}$, standard error.

Table 6 Univariate analysis of the factors that were divided by sex

\begin{tabular}{|c|c|c|c|}
\hline & Males & Females & $P$-value \\
\hline $\begin{array}{l}\text { Percentage of eligible } \\
\text { cases (\%) }\end{array}$ & $38.5 \%(122 / 317)$ & $29.4 \%(72 / 245)$ & 0.024 \\
\hline Cecal intubation time (s) & I,193.8/655.5 & I,355.4/736.2 & 0.006 \\
\hline Age (years) mean $\pm S D$ & $63.1 \pm 10.0$ & $62.9 \pm 10.6$ & 0.788 \\
\hline BMI $\left(\mathrm{kg} / \mathrm{m}^{2}\right)$ mean $\pm \mathrm{SD}$ & $22.7 \pm 3.1$ & $22.3 \pm 4.1$ & 0.141 \\
\hline $\begin{array}{l}\text { Waist circumference }(\mathrm{cm}) \\
\text { mean } \pm \text { SD }\end{array}$ & $84.0 \pm 9.2$ & $76.8 \pm 11.9$ & $<0.0001$ \\
\hline Hypertension (\%) (yes/no) & $47.9 \%(152 / 165)$ & $37.6 \%(92 / 153)$ & 0.014 \\
\hline Diabetes (\%) (yes/no) & $16.4 \%(52 / 265)$ & $14.3 \%(35 / 210)$ & 0.492 \\
\hline $\begin{array}{l}\text { Hyperlipidemia (\%) } \\
\text { (yes/no) }\end{array}$ & $18.3 \%(58 / 259)$ & $18.8 \%(46 / 199)$ & 0.885 \\
\hline $\begin{array}{l}\text { History of abdominal } \\
\text { surgery (\%) (yes/no) }\end{array}$ & $35.6 \%(113 / 204)$ & $46.5 \%(|| 4 /|3|)$ & 0.009 \\
\hline $\begin{array}{l}\text { Taking antithrombotics } \\
\text { (\%) (yes/no) }\end{array}$ & $16.1 \%(51 / 266)$ & $12.7 \%(3|/ 2| 4)$ & 0.253 \\
\hline Diverticula (\%) (yes/no) & $37.2 \%(118 / 199)$ & $23.3 \%(57 / / 88)$ & $<0.0001$ \\
\hline $\begin{array}{l}\text { Bowel preparation (\%) } \\
\text { (good/poor) }\end{array}$ & $87.4 \%(277 / 40)$ & $89.8 \%(220 / 25)$ & 0.376 \\
\hline
\end{tabular}

Abbreviation: BMI, body mass index.
Table 8 Multivariate analysis of the study factors in the eligible cases and non-eligible cases that were divided by sex

\begin{tabular}{lllll}
\hline Males & Odds Ratio & SE & P-value & 95\% Cl \\
\hline Age & 1.032 & 0.012 & 0.009 & $1.008,1.056$ \\
Taking antithrombotics & 1.767 & 0.626 & 0.108 & $0.882,3.538$ \\
Bowel preparation & 3.200 & 1.408 & 0.008 & $1.350,7.58 \mathrm{I}$ \\
\hline Females & Odds Ratio & SE & P-value & $\mathbf{9 5 \%} \mathbf{C l}$ \\
\hline BMI & 0.881 & 0.065 & 0.087 & $0.763,1.018$ \\
Waist circumference & 1.014 & 0.259 & 0.589 & $0.964,1.066$ \\
Hypertension & 0.417 & 0.126 & 0.004 & $0.230,0.754$ \\
Bowel preparation & 4.039 & 3.076 & 0.067 & $0.908,17.969$ \\
\hline
\end{tabular}

Abbreviations: $\mathrm{BMI}$, body mass index; $\mathrm{Cl}$, confidence interval; SE, standard error.

analysis performed separately for males and females found that among eligible male cases, patients were younger (61.1 \pm 9.7 vs $64.4 \pm 10.0$ years; $P=0.005$ ), fewer were taking antithrombotic agents $(10.7 \%$ vs $19.5 \% ; P=0.040)$, and a higher proportion had good bowel preparation $(94.3 \%$ vs $83.1 \% ; P=0.005$ ) (Table 7). Multivariate analysis of only the factors with $P<0.1$ found significant differences for younger age $(P=0.009)$ and good bowel preparation $(P=0.008)$ (Table 8). Eligible female cases had a higher BMI (23.7 \pm 4.9 vs $\left.21.7 \pm 3.6 \mathrm{~kg} / \mathrm{m}^{2} ; P=0.001\right)$, larger waist circumference ( $80.1 \pm 13.4$ vs $75.6 \pm 11.0 \mathrm{~cm} ; P=0.006)$, higher incidence of hypertension $(59.7 \%$ vs $30.1 \% ; P<0.0001)$, and higher proportion of good bowel preparation $(97.2 \%$ vs $86.7 \%$; $P=0.025$ ) compared to ineligible cases (Table 7). Multivariate analysis of only the factors with $P<0.1$ found a significant difference among cases with hypertension $(P=0.004)$ (Table 8$)$.

\section{Discussion}

The present study found that metabolic-related factors can affect the CIT of physicians in training. The eligible cases had a significantly higher proportion of males, younger patients, patients with higher BMI, those with good bowel

Table 7 Univariate analysis of the factors that were divided by sex in the eligible cases and non-eligible cases

\begin{tabular}{|c|c|c|c|c|c|c|}
\hline & \multicolumn{3}{|l|}{ Males $(n=3 \mid 7)$} & \multicolumn{3}{|c|}{ Females $(n=245)$} \\
\hline & $\begin{array}{l}\text { Eligible } \\
(n=122)\end{array}$ & $\begin{array}{l}\text { Non-eligible } \\
(n=195)\end{array}$ & P-value & $\begin{array}{l}\text { Eligible } \\
(n=72)\end{array}$ & $\begin{array}{l}\text { Non-eligible } \\
(n=173)\end{array}$ & P-value \\
\hline Cecal insertion time $(s)$ mean $\pm S D$ & $635.0 \pm 167.8$ & $1,543 \pm 602.6$ & $<0.0001$ & $647.9 \pm 170.1$ & $1,649.9 \pm 678.3$ & $<0.0001$ \\
\hline Age (years) mean $\pm S D$ & $61.1 \pm 9.7$ & $64.4 \pm 10.0$ & 0.005 & $63.1 \pm 11.3$ & $62.8 \pm 10.4$ & 0.819 \\
\hline $\mathrm{BMI}\left(\mathrm{kg} / \mathrm{m}^{2}\right)$ mean $\pm \mathrm{SD}$ & $22.9 \pm 3.0$ & $22.6 \pm 3.1$ & 0.355 & $23.7 \pm 4.9$ & $21.7 \pm 3.6$ & 0.001 \\
\hline Waist circumference $(\mathrm{cm})$ mean $\pm S D$ & $84.0 \pm 8.9$ & $84.0 \pm 9.4$ & 0.993 & $80.1 \pm 13.4$ & $75.6 \pm 11.0$ & 0.006 \\
\hline Hypertension (\%) (yes/no) & $52.5 \%(64 / 58)$ & $45.1 \%(88 / 107)$ & 0.204 & $59.7 \%(43 / 29)$ & $30.1 \%(52 / 121)$ & $<0.0001$ \\
\hline Diabetes (\%) (yes/no) & $13.9 \%(17 / 105)$ & $17.9 \%(35 / 160)$ & 0.349 & $18.1 \%(13 / 59)$ & $12.7 \%(22 /|5|)$ & 0.279 \\
\hline Hyperlipidemia (\%) (yes/no) & $22.1 \%(27 / 95)$ & $15.9 \%(31 / 164)$ & 0.164 & $12.5 \%(9 / 63)$ & $21.1 \%(37 / 136)$ & 0.109 \\
\hline History of abdominal surgery (\%) (yes/no) & $35.2 \%(43 / 79)$ & $35.9 \%(70 / 125)$ & 0.906 & $40.3 \%(29 / 43)$ & $49.1 \%(85 / 88)$ & 0.207 \\
\hline Taking antithrombotics (\%) (yes/no) & $10.7 \%(13 / 109)$ & $19.5 \%(38 / 157)$ & 0.040 & $16.7 \%(12 / 60)$ & $11.0 \%(19 / 153)$ & 0.226 \\
\hline Diverticula (\%) (yes/no) & $36.9 \%(45 / 77)$ & $37.4 \%(73 / 122)$ & 0.921 & $26.4 \%(19 / 53)$ & $22.0 \%(38 / 135)$ & 0.456 \\
\hline Bowel preparation (\%) (good/poor) & $94.3 \%(115 / 7)$ & $83.1 \%(162 / 33)$ & 0.005 & $97.2 \%(70 / 2)$ & $86.7 \%(150 / 23)$ & 0.025 \\
\hline
\end{tabular}

Abbreviation: BMI, body mass index. 
preparation, and those with hypertension. Furthermore, in separate analyses for males and females, eligible male cases had a higher proportion of younger patients and those with good bowel preparation, while among females there were a higher proportion of patients with hypertension.

A prior report asserted that females have longer colons, which more easily form loops due to a deeper and rounder pelvis. ${ }^{15}$ Females are also considered to have less visceral fat, resulting in less tissue supporting the colon than in males thus making endoscope insertion more difficult. ${ }^{16}$ Older age was associated with longer CIT, as the elasticity of the colon decreases and loops are formed more easily with increasing age. ${ }^{8}$ Previous studies also found that patients with lower BMI were more difficult to intubate. ${ }^{8,9} \mathrm{BMI}$ is correlated with visceral fat, and there is more robust colon support when there is more visceral fat, resulting in less loop formation during CS. Obese patients are also said to have shorter colons. ${ }^{8}$ When bowel preparation is poor, the difficulty in clearing a field of view during insertion can conceivably cause insertion difficulties. ${ }^{17}$

In our study, hypertension, diabetes, hyperlipidemia, and CIT were studied as metabolic syndrome-related factors. This study newly discovered a higher proportion of eligible cases among patients with hypertension; no prior reports investigated a relationship between hypertension and CIT. It is believed that there are more eligible cases among hypertensive patients in whom the sympathetic nervous system is dominant, and conversely a suppressed parasympathetic nervous system could reduce bowel peristalsis, facilitating endoscope insertion. In fact, patients using antispasmodics have been reported to have a shorter CIT. ${ }^{18,19}$ Antispasmodics were not used in our study, so there is the possibility that endoscope insertion caused difficulty in cases with active bowel peristalsis, or, in other words, cases with a dominant parasympathetic nervous system and reduced blood pressure. It may be necessary to collect data on the autonomous nervous system in the future when elucidating the relationship between the autonomous nervous system and endoscopic examination.

Prior studies have also reported that the CIT is longer in cases with a history of abdominal surgery, but cases of appendectomy were included in the current study, resulting in the possibility that a correlation could not be obtained. Additionally, many prior investigations have used sedatives, ${ }^{8,9,12}$ but sedatives were not used in the present study, resulting in the possibility that the inclusion of cases with strong patient pain as an indicator for involvement of a fellow physician during the procedure caused our results to differ from the preceding reports. Additionally, although this may be a characteristic of the tertiary care center in the current investigation, it cannot be denied that the use of many different endoscopes could have had an effect on insertion times.

Considering the characteristics of CS cases that should be presided over by an endoscopist in training based on the above results, such physicians should start with males because of the higher percentage of eligible cases among them. A plan of presiding over younger male patients and quickly replacing the trainee with an expert physician if poor bowel preparation is discovered could conceivably reduce patient pain and enable efficient cultivation of technique for physicians in training. Among female patients, physicians in training should preside over patients with hypertension.

A limitation of this study is that it was conducted at a single institution, and being a tertiary health care facility could have caused a bias in the cases analyzed. Due to being a retrospective study, further verification is considered necessary through a prospective investigation estimating which cases have a high likelihood of being eligible based on the present results. Few studies have separately investigated expert physicians and physicians in training, ${ }^{13}$ and few reports have investigated the characteristics of cases where a physician in training was able to reach the cecum without being replaced by an expert physician within a stipulated length of time. ${ }^{4}$ As a result, there was almost no evidence indicating which types of cases a physician in training for CS should initially conduct. The present results can enable more efficient development of $\mathrm{CS}$ insertion technique and reduce patient pain.

\section{Conclusion}

This study is the first report to investigate the CIT during CS with regard to the metabolic syndrome-related factors of hypertension, diabetes, and hyperlipidemia, which has resulted in extremely useful findings for considering cases over which a physician in training should preside.

\section{Acknowledgments}

The authors express deep gratitude to Dr Takaharu Matsunaga and Dr Satoko Kaneyama for their guidance and useful discussions.

\section{Author contributions}

R Kawasato drafted the manuscript. S Hashimoto performed analysis and interpretation of the data. T Shirasawa, A Goto, T Okamoto, and J Nishikawa were involved in conception and design. I Sakaida approved the final manuscript. All authors contributed toward data analysis, drafting and revising the paper and agree to be accountable for all aspects of the work. 


\section{Disclosure}

All authors report no conflict of interest in this work.

\section{References}

1. Toshiharu G, Kunichika M, Kayoko H, Takefumi K, Kanako S, Tomonori H. [Estimation of cost of illness (COI) for colon cancer]. The Journal of Japan Society for Health Care Management. 2015;16(1):2-7. Japanese.

2. Saito H, Machii R, Takahashi M, Saito K. [Evidence on colorectal cancer screening and a perspective on future research]. Nihon Shokakibyo Gakkai Zasshi. 2014;111(3):453-463. Japanese.

3. Winawer SJ, Zauber AG, Ho MN, et al. Prevention of colorectal cancer by colonoscopic polypectomy. N Engl J Med. 1993;329(27) 1977-1983.

4. Park HJ, Hong JH, Kim HS, et al. Predictive factors affecting cecal intubation failure in colonoscopy trainees. BMC Med Educ. 2013;13:5.

5. Anderson ML, Pasha TM, Leighton JA. Endoscopic perforation of the colon: lessons from a 10-year study. Am J Gastroenterol. 2000;95(12): 3418-3422.

6. Kenichi S, Tomohiko S, Ohoishi K, Ori T. Simple and inexpensive handmade model for colonoscopy training. Progress of Digestive Endoscopy. 2012;81(2):39-43.

7. Anderson JC, Messina CR, Cohn W, et al. Factors predictive of difficult colonoscopy. Gastrointest Endosc. 2001;54(5):558-562.

8. Krishnan P, Sofi AA, Dempsey R, Alaradi O, Nawras A. Body mass index predicts cecal insertion time: the higher, the better. Dig Endosc. 2012;24(6):439-442.

9. Hsieh YH, Kuo CS, Tseng KC, Lin HJ. Factors that predict cecal insertion time during sedated colonoscopy: the role of waist circumference. J Gastroenterol Hepatol. 2008;23(2):215-217.
10. Chung GE, Lim SH, Yang SY, et al. Factors that determine prolonged cecal intubation time during colonoscopy: impact of visceral adipose tissue. Scand J Gastroenterol. 2014;49(10):1261-1267.

11. Liang CM, Chiu YC, Wu KL, et al. Impact factors for difficult cecal intubation during colonoscopy. Surg Laparosc Endosc Percutan Tech. 2012;22(5):443-446.

12. Nagata N, Sakamoto K, Arai T, et al. Predictors for cecal insertion time: the impact of abdominal visceral fat measured by computed tomography. Dis Colon Rectum. 2014;57(10):1213-1219.

13. Jia H, Wang L, Luo H, et al. Difficult colonoscopy score identifies the difficult patients undergoing unsedated colonoscopy. BMC Gastroenterol. 2015;15:46

14. Chak A, Cooper GS, Blades EW, Canto M, Sivak MV Jr. Prospective assessment of colonoscopic intubation skills in trainees. Gastrointest Endosc. 1996;44(1):54-57.

15. Saunders BP, Fukumoto M, Halligan S, et al. Why is colonoscopy more difficult in females? Gastrointest Endosc. 1996;43(2 Pt 1): 124-126.

16. Krotkiewski M, Bjorntorp P, Sjöström L, Smith U. Impact of obesity on metabolism in men and females. Importance of regional adipose tissue distribution. J Clin Invest. 1983;72(3):1150-1162.

17. Cheng RW, Chiu YC, Wu KL, et al. Predictive factors for inadequate colon preparation before colonoscopy. Tech Coloproctol. 2015;19(2): 111-115.

18. Saunders BP, Williams CB. Premedication with intravenous antispasmodic speeds colonoscope insertion. Gastrointest Endosc. 1996;43(3) 209-211.

19. Marshall JB, Patel M, Mahajan RJ, Early DS, King PD, Banerjee B. Benefit of intravenous antispasmodic (hyoscyamine sulfate) as premedication for colonoscopy. Gastrointest Endosc. 1999;49(6): $720-726$.

\section{Clinical and Experimental Gastroenterology}

\section{Publish your work in this journal}

Clinical and Experimental Gastroenterology is an international, peerreviewed, open access, online journal publishing original research, reports, editorials, reviews and commentaries on all aspects of gastroenterology in the clinic and laboratory. This journal is included on PubMed. The manuscript management system is completely online

\section{Dovepress}

and includes a very quick and fair peer-review system, which is all easy to use. Visit http://www.dovepress.com/testimonials.php to read real quotes from published authors. 